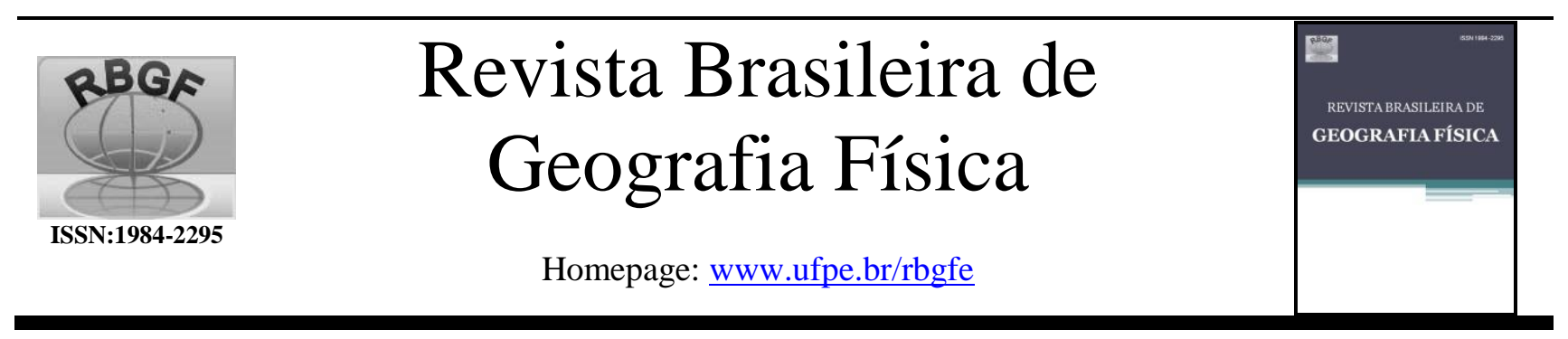

\title{
Contribuições da mineração para o município na perspectiva da sustentabilidade
}

\author{
Heline Fernanda S. de Assis Dantas ${ }^{1}$ Lúcia Santana de Freitas ${ }^{2}$ \\ 1 Graduada em Geografia pela Universidade Estadual da Paraíba - UEPB; Mestre em Recursos Naturais - UFCG, \\ Doutoranda em Recursos Naturais - Universidade Federal de Campina Grande UFCG - PB Autor correspondente: \\ helinefernanda@hotmail.com \\ ${ }^{2}$ Doutora em Administração pela Universidade de Valladolid-Espanha (2001). Atualmente é professora Associado III \\ da Universidade Federal de Campina Grande. Atua nas áreas de ensino e pesquisa. professora permanente do Programa \\ de Pós-Graduação em Recursos Naturais da UFCG, Lucia.sdefreitas@gmail.com \\ Trabalho referente a tese intitulada "Análise da relação entre o nível de sustentabilidade da atividade mineral com a \\ sustentabilidade dos municípios produtores de minérios na Região do Seridó Paraibano".
}

Artigo recebido em 30/03/2017 e aceito em 25/06/2018

\section{RE S U M O}

O objetivo deste trabalho foi expor algumas contribuições da atividade mineral para seus respectivos municípios. Neste contexto, foram explorados uma visão mais ampla da atividade mineral, assim como benefícios econômicos, além de alguns entraves ambientais e sociais enfrentados pelo setor. Dessa forma, expõem-se os benefícios que os sistemas de indicadores para a atividade mineral trazem para um bom desempenho da mesma e, por outro lado, as dificuldades de se avaliar uma atividade econômica tão intrínseca e com tantas peculiaridades, mas que pode ser desenvolvida de forma sustentável. Entretanto, para isso é preciso compreender o espaço dinamizado onde ocorrem essas atividades e propor novas formas para desenvolver a dinâmica do local, trabalhando com indicadores de sustentabilidade municipal como forma mais ampla de perceber como essa atividade econômica pode influenciar para a sustentabilidade do município. Portanto, percebe-se que essas contribuições são mais evidenciadas através do bom desempenho e uso que receitas como a CFEM (Compensação financeira por Exploração de Recursos Minerais), quando geridas no município, direcionando, assim, ações de bem-estar social, multiplicação da renda e do emprego, fortalecimento institucional, apoio a outras atividades econômicas, como também a utilização mais eficiente desta renda mineral gerada. Palavras Chave: Mineração, indicadores de sustentabilidade, sustentabilidade municipal.

\section{Contributions of mining activity to the municipality in the perspective of sustainability}

\begin{abstract}
A B S T R A C T
The aim of this work was to highlight some contributions of mining activity to the correspondent municipalities. In this context, it was considered a wider view of mining activity, as well as the economic benefits from it, and the environmental and social issues faced by the sector. Then, it is shown the benefits that the systems of indicators for the mining activity bring to a good performance of this activity, and, on the other hand, the difficulties of evaluating an economic activity so intrinsic and with so many peculiarities, but that can develop the sustainability. However, it is necessary to comprehend the space and its dynamic where these activities take place in order to propose new strategies of developing the local dynamics, working with indicators of municipal sustainability as a wider manner of understanding how this economic activity can affect the municipality and its sustainability. Therefore, these contributions are more evidenced by the good performance and the use of the incomes like the Financial Compensation for the Exploration of Mineral Resources - CFEM when managed in the municipality, thus directing actions toward the social welfare, income improvement and employment, institutional strengthening, support to other economic activities, as well as a more efficient utilization of this income generated from the mining activity.
\end{abstract}

Keywords: Mining, sustainability indicators, municipal sustainability. 


\section{Introdução}

A tendência atual de gestão é pensar em desenvolvimento embasado em preceitos sustentáveis, uma vez que os municípios estão cada vez maiores e suas formas de gestão nem sempre seguem esses preceitos economicamente viável, socialmente justo e ambientalmente sustentável.

Segundo Vasconcellos (2002), a partir da Constituição de 1988, os municípios se tornaram importantes protagonistas do controle das questões ambientais locais. As leis Orgânicas Municipais, os Planos Diretores e a nova legislação municipal específica sobre as questões relativas ao meio ambiente foram elaborados e estão sendo implementados de forma desigual, de acordo com as variadas realidades municipais.

Sendo assim, há aqui o intuito de propor novas estratégias que busquem proporcionar um ambiente agradável para o desempenho de atividades sustentáveis, principalmente nos municípios que desenvolvem atividades altamente impactantes ao meio ambiente, como é o caso das atividades de extração mineral. Neste diapasão, surgem, cada vez mais, novas estratégias de desenvolvimento relacionadas às questões de sustentabilidade. Apesar de que alguns municípios tornam-se vulneráveis a essas atividades, uma vez que, em sua maioria as questões econômicas sempre prevalecem sobre as demais.

Braga (2003) afirma que um município é considerado mais ou menos sustentável na medida em que é capaz de manter ou melhorar a saúde de seu sistema ambiental, minorar a degradação e o impacto antrópico, reduzir a desigualdade social, prover os habitantes de condições básicas de vida, como também prover seus habitantes de um ambiente saudável e seguro, bem como construir pactos políticos que permitam enfrentar desafios presentes e futuros.

Entretanto, desenvolver possibilidades de trabalhar harmoniosamente com os recursos minerais finitos e fazer com que eles sejam vistos dentro dos pilares da sustentabilidade, de fato, são alternativas que contrariam em grande parte o crescimento econômico do mundo atual, uma vez que há uma imensa dependência desses recursos.

Estabelecer alternativas que façam com que os recursos minerais garantam sua permanência para as futuras gerações é um dos maiores desafios da humanidade. O setor mineral sempre foi visto pela valorização econômica, e visualizá-lo sob outras dimensões como a social e a ambiental inevitavelmente possibilitaria desenvolver uma nova visão para o setor, que sempre foi e continua sendo visto como degradante ao meio ambiente.

Portanto, analisar as contribuições da mineração para os municípios com atividade mineral, de fato, é de suma importância, haja vista a possibilidade de conhecer as dinâmicas e peculiaridades que essa atividade pode gerar, bem como estratégias de gestão através de indicadores de sustentabilidade, uma vez que tais indicadores tornam-se instrumentos de análises para que se possa averiguar a sustentabilidade da atividade mineral, assim como o desenvolvimento dos municípios.

Diante do exposto, o presente ensaio tem como objetivo analisar as contribuições que a atividade mineral pode gerar para desenvolvimento municipal na perspectiva da sustentabilidade. Neste contexto, pretende-se mostrar a importância da atividade de mineração, suas contribuições para a sustentabilidade dos municípios, bem como possibilidades do uso de indicadores de sustentabilidade para avaliar o desenvolvimento municipal e da atividade mineral.

\section{Mineração e Sustentabilidade}

\section{A mineração $e$ seus preceitos para a sustentabilidade}

A atividade mineral sempre foi de grande importância para o desenvolvimento de uma região. Ela surge como alternativa de crescimento, e hoje também como novas possibilidades de desenvolver uma atividade mais centrada no viés da sustentabilidade. Pode-se dizer que a atividade de extração mineral se constitui num importante fator de desenvolvimento nacional tendo por características contribuir significativamente para a geração de renda, exportações e saldo positivo na balança comercial do país.

Entretanto, se por um lado a atividade mineral gera crescimento; por outro, pode gerar imensas áreas de conflitos, sejam eles ambientais, sociais e até mesmo econômicos. Trabalhar com recurso finito dentro dos pilares da sustentabilidade não se torna tarefa fácil, mas também não é impossível perante a abundância de recursos inerentes à essa atividade.

O Brasil, por ser um território que desde o início da sua colonização vem explorando seus recursos minerais até os dias atuais, apresenta uma gama de possibilidades de desenvolver trabalhos discutindo, analisando ou propondo alternativas de atuação sustentável para o setor mineral. 
Embora as questões econômicas neste setor sejam bem mais preponderantes que as ambientais, alguns órgãos foram criados para que se tenha certo controle sobre a exploração mineral, como: IBRAM, CETEM, DNPM, entre outros, desenvolvedores de programas de pesquisa, controle e desenvolvimento da atividade mineral.

Entretanto, Lins et al. (2000) afirmam que a importância da mineração para a economia brasileira pode ser subestimada se for considerada apenas sua participação no PIB nacional, algo em torno de $1 \%$ (incluído o petróleo e o gás). Ainda assim, o seu papel no cenário econômico eleva-se substancialmente com a agregação de frações de outros subsetores que fornecem insumos para a mineração (em sua atividade extrativa strictu sensu de produção na própria mina) e daqueles subsetores que dela dependem parcialmente, formando o elo da cadeia produtiva.

Viana (2012) afirma que atualmente o Brasil é um dos maiores produtores e exportadores de vários minérios, com destaque para nióbio e minério de ferro $\left(1^{\circ}\right.$ lugar no mundo), manganês, tantalita e bauxita $\left(2^{\circ}\right)$, grafite $\left(3^{\circ}\right)$ e rochas ornamentais $\left(4^{\circ}\right)$. Todavia, no que tange às carências, nosso país apresenta dependência externa em relação a alguns minerais importantes para a economia, tais como carvão mineral e insumos essenciais para a fabricação de fertilizantes.

Apesar disso, a mineração é uma atividade em alta nas cotações internacionais, principalmente devido à demanda por minerais pelos países emergentes, em especial China e Índia. O Brasil tem se beneficiado bastante com o aumento dos preços internacionais, exportando cerca de $70 \%$ de sua produção interna e batendo recordes de produção e de receitas de exportação, sendo um dos 10 maiores países produtores do mundo (Fernandes et al., 2011).

Para (Kopezinki, 2000) "É inegável que, no mundo moderno, a mineração assume contornos de importância decisiva para o desenvolvimento, pois se observa que o minério extraído da natureza está em quase todos os produtos utilizados: Entretanto, esta dependência gera um ônus para a sociedade, ou seja, o surgimento de imensas áreas degradadas que, ao final da exploração, na maioria das vezes, não podem ser ocupadas racionalmente.

É sabido que esta atividade pode causar no território destruição da vegetação, alteração da paisagem local e perturbação do ecossistema, acarretando baixa qualidade de vida, principalmente se não for conduzida em bases sustentáveis, pois geralmente acarreta consequências à área de exploração, sobretudo pela descarga de resíduos sólidos, líquidos e gasosos (Strauch et al., 2011).

Entretanto, os minerais são absolutamente necessários à existência e ao bem-estar humano, já que grande parte das matérias-primas e da energia é disponibilizada pela mineração, a partir de substâncias minerais metálicas e não metálicas. Contudo, apesar dessa importância, o setor mineral utiliza recurso natural exaurível, cujas operações de extração, invariavelmente, levam a uma variedade de impactos ambientais, incluindo a exaustão dos recursos não renováveis, a perturbação da paisagem e ameaças acima da média para a saúde e segurança dos trabalhadores e dos cidadãos (Moreira 2003; Azapagic 2004).

Sendo assim, Barreto (2001) afirma ficar subentendido que a mineração como atividade econômica deve se comprometer não só em buscar a maximização do uso dos recursos minerais sob o ponto de vista técnico e econômico, mas, sobretudo, contribuir para construção de um modelo de desenvolvimento econômico capaz de gerar condições de acumulação de capital e tecnologia e, ao mesmo tempo, de assegurar a salubridade ambiental, de forma que, após a desativação e o fechamento de minas, o uso das áreas mineradas permita a contínua agregação de valores econômicos e sociais às comunidades locais e à sociedade.

Em termos práticos, todas as atividades relacionadas à mineração - da pesquisa à lavra deverão prever, ainda segundo Barreto (2001), os riscos e a proteção dos impactos ambientais; monitoramento e a recuperação das áreas degradadas, de forma continua; compartilhamento de benefícios econômicos com a sociedade, em especial as comunidades locais; uso futuro da área minerada; e o desenvolvimento das comunidades vizinhas.

No Brasil, quanto aos aspectos legais, o primeiro dispositivo jurídico visando a minimizar os impactos negativos causados por mineração foi a Lei $n^{\circ} 6938$, de 31/08/1981, que, através do Decreto Federal $\mathrm{n}^{\mathrm{o}}$ 88.351, instituiu o Licenciamento Prévio (LP), Licenciamento de Instalação (LI) e Licenciamento de Operação (LO). A partir de 1986, com a Resolução do CONAMA $n^{\circ} 01$, estabeleceram-se as definições, as responsabilidades, os critérios básicos e as diretrizes gerais para o uso e implementação da Avaliação de Impactos Ambientais (AIA) como instrumento da Política Nacional do Meio Ambiente.

Para que esses recursos sejam maximizados, agregam-se a eles compensações 
financeiras. Deste modo, criam-se de forma compensatória benefícios em relação às ações das áreas mineradoras e seus municípios. Entretanto, a Constituição Federal de 1988 estabelece que são bens da União, entre outros, os "recursos minerais, inclusive o subsolo" (art. 20 inciso IX). No $\S 1^{\circ}$ do mesmo artigo, a Lei Maior assegura aos Estados, Distrito Federal, Municípios e órgãos da administração direta da União participação no resultado da exploração de petróleo, gás natural e outros recursos minerais ou compensação financeira por essa exploração, a chamada (Compensação financeira por Exploração de Recursos Minerais - CFEM).

Em 1989, o Decreto Federal $n^{\circ} 97.632$ definiu, em seu artigo $1^{\circ}$, que os empreendimentos que se destinam à exploração dos recursos minerais deverão submeter seus projetos à aprovação dos órgãos federais, estaduais e municipais competentes, que deverão executar o Estudo de Impacto Ambiental (EIA), o Relatório de Impacto Ambiental, bem como o Plano de Recuperação de Áreas Degradadas (PRAD). E aqueles empreendimentos já existentes deverão regularizar sua situação por meio de um PRAD.

Por sua vez, o Código de Mineração, Lei 9.314/96 institui, em seu art. $1^{\circ}$, que "compete à União administrar os recursos minerais, a indústria de produção mineral e a distribuição, o comércio e o consumo de produtos minerais. No seu art. $2^{\circ}$, estabelece os cinco regimes de aproveitamento das substâncias minerais, quais sejam: concessão, autorização, licenciamento, permissão de lavra garimpeira e monopolização.

Apesar de em 2011 surgir a proposta de Lei $\mathrm{n}^{0} 37 / 2011$, visando reformular o código para modernizar mais o sistema e facilitar os processos de autorização de pesquisa e lavra; ainda assim, a acelerada degradação dos recursos naturais está comprometendo a qualidade de vida das atuais e das futuras gerações, criando a necessidade da sociedade buscar alternativas que harmonizem o desenvolvimento econômico à preservação, proteção e recuperação do meio ambiente. Essas alternativas são indicativos de que a proteção ambiental está deixando de ser considerada responsabilidade exclusiva dos órgãos de meio ambiente, passando a ser dividida por todos os setores da sociedade, como descrito no artigo 225 da Constituição Federal, onde diz que "Todos têm direito ao meio ambiente ecologicamente equilibrado, bem de uso comum do povo e essencial à sadia qualidade de vida, impondo-se ao poder público e à coletividade o dever de defendê-lo e preservá-lo para as presentes e futuras gerações".
Para Barreto (2001), a simplificação da legislação ambiental, afim de se obter eficiência normativa, é uma questão que está inserida na busca do desenvolvimento sustentável. A legislação ambiental se não for simples e clara, serve como complicador para as atividades econômicas, estimulando a ilegalidade e a corrupção. É necessário um sistema legal eficiente e eficaz para que essas práticas não ocorram.

Para tanto, a consolidação do Novo Código de Mineração traz alguns desses pontos já regulamentados e incorporados. Mesmo que seja lento todo o processo, pode-se verificar o grande passo que o Brasil dá neste campo. Com a consolidação do Código, a mineração chega a fazer parte mais direta de suas ações e benefícios, principalmente para as áreas onde estão localizadas. Além do crescimento econômico, o avanço no âmbito ambiental e social fará toda a diferença para a atividade.

O Quadro 01, vê-se a distribuição das atribuições governamentais em relação à proteção ambiental e planejamento da mineração.

Todas essas atribuições explanam a forma legal através da qual a atividade de mineração deve ser exercida para que seja bem planejada e bem executada, fazendo com que alguns problemas, principalmente de cunho ambiental, não venham a prejudicar uma determinada área ou um determinado mineral, diminuindo então as chances de se ter uma extração mal sucedida e impossibilitando a área para futuras ações.

Dessa forma, o usufruto dos recursos minerais necessita do estabelecimento de critérios, principalmente para as questões de ordem ambiental e social. O modo como se dá o uso dos recursos naturais é fator determinante no processo de construção de um desenvolvimento sustentável, em qualquer de suas dimensões, fazendo-se necessário que a sociedade incorpore a ideia de que os recursos naturais apenas estarão disponíveis, para esta e para as futuras gerações, se utilizados de modo racional e em consonância com os tempos necessários à sua geração e reposição. O fato é que a observância desses tempos muitas vezes não se adéqua às necessidades associadas ao crescimento populacional, gerando situações que ameaçam espécies e condições materiais como um todo.

A grande questão em administrar esses conflitos entre os diferentes agentes e interesses envolvidos, sem que não deixe de explorar os minerais, passa por acordos que levem em conta o interesse das empresas do ramo mineral e, principalmente, aqueles dos pequenos mineradores, bem como da população local. 
Quadro 01 - Distribuição das Atribuições Governamentais em Relação à Proteção ambiental e Planejamento da

\begin{tabular}{|l|l|l|l|}
\hline Atividade de mineração & Poder Municipal & Poder Estadual & Poder Federal \\
\hline $\begin{array}{l}\text { Requerimento de } \\
\text { concessão de licença }\end{array}$ & $\begin{array}{l}\text { Leis de Uso e ocupação } \\
\text { do Solo }\end{array}$ & $\begin{array}{l}\text { Licença Ambiental por } \\
\text { Legislação Federal }\end{array}$ & $\begin{array}{l}\text { Deferimento } \\
\text { Indeferimento }\end{array}$ \\
\hline Pesquisa Mineral & $\begin{array}{l}\text { Leis de Uso e ocupação } \\
\text { do Solo }\end{array}$ & $\begin{array}{l}\text { Licença Ambiental por } \\
\text { Legislação Federal }\end{array}$ & $\begin{array}{l}\text { Acompanhamento } \\
\text { Aprovação Negação }\end{array}$ \\
\hline Lavra Mineral & $\begin{array}{l}\text { Alvará } \\
\text { funcionamento }\end{array}$ & $\begin{array}{l}\text { Análise do EIA/RIMA } \\
\text { e Licença Ambiental } \\
\text { por Legislação Federal }\end{array}$ & $\begin{array}{l}\text { Acompanhamento } \\
\text { Fiscalização }\end{array}$ \\
\hline $\begin{array}{l}\text { Recuperação da área } \\
\text { minerada }\end{array}$ & $\begin{array}{l}\text { Definição do uso futuro } \\
\text { do solo }\end{array}$ & $\begin{array}{l}\text { Futuro do Solo Criado } \\
\text { Licença Ambiental por } \\
\text { Legislação Federal }\end{array}$ & \\
\hline
\end{tabular}

Fonte: Farias (2002)

\section{Dimensão Econômica da Mineração para a sustentabilidade}

Estabelecer relação sustentável a um recurso finito, é sem sombra de dúvidas um desafio ousado, mas essa realidade já se encontra em várias literaturas atuais. O propósito da ideia é tentar mostrar que apesar das dificuldades em visualizar uma prática mais abrangente da mesma, sempre haverá maneiras de desenvolver uma atividade, principalmente a de mineração, com mais responsabilidade. Entretanto suje pressupostos que antes pouco se admitia para o processo principalmente de extração mineral nos países em fase de desenvolvimento dito o Brasil. A forma com vem tomando esse desenvolvimento estende a porções menores da cadeia de produção, de modo a se imaginar que num futuro bem próximo se possa ver um virtuoso desenvolvimento para as pequenas minas $\mathrm{e}$ minerações.

Entretanto, na atividade mineral, ainda são tímidas as ações, sobretudo no que tange as questões de sustentabilidade, visto tratar-se de atividade de recursos naturais finitos, fato que, dificulta o entendimento de a mesma poder um dia mostrar-se sustentável.

Por ser um espaço onde desde o início de sua colonização até os dias atuais vem se explorando recursos minerais, o Brasil conta com uma gama de trabalhos discutindo, analisando ou propondo alternativas de desenvolvimento sustentável para o setor mineral.

O fato é que hoje o Brasil abriga um dos maiores potenciais minerais do mundo, propiciado por uma diversificada constituição geológica e pelas dimensões continentais do País (Viana, 2007).

Entretanto, Kopezinki (2000) afirma: "É inegável que, no mundo moderno, a mineração assume contornos de importância decisiva para o desenvolvimento, pois se observa que o minério extraído da natureza está em quase todos os produtos utilizados. Dessa forma, esta dependência gera um ônus para a sociedade, ou seja, o surgimento de imensas áreas degradadas que, ao final da exploração, na maioria das vezes, não podem ser ocupadas racionalmente.

Nesse sentido, entende-se que o principal agente regulador é o Estado, uma vez que está estabelecido na Constituição Federal de 1988 que os recursos minerais são bens da União e que a ela cabe regulamentá-los. Entretanto, a sua utilização econômica nos transmite uma contraprestação - a compensação financeira pela exploração Mineral ( CFEM).

De acordo com o Departamento Nacional de Produção Mineral - DNPM (2013), o disposto no Art. $3^{\circ}$, inciso IX da Lei $n^{\circ} 8.876 / 94$, cabe-lhe baixar normas e exercer a fiscalização sobre a arrecadação da CFEM, que é devida a todos aqueles que, para fins econômicos, explorem recursos minerais, retirando substâncias minerais da jazida, mina, salina ou outro depósito mineral.

Dos recursos do CFEM, $12 \%$ destinam-se à União (DNPM e IBAMA), $23 \%$ aos estados onde é extraída a substância mineral e 65\% aos municípios produtores. Além da CFEM e dos tributos comuns a qualquer atividade econômica, principalmente o ICMS, a mineração está sujeita a encargos específicos, como o pagamento de taxas e emolumentos ao DNPM. 
Nesse sentido, Azapagic (2004) argumenta que essas e outras questões levaram a indústria mineral a se envolver no debate sobre a sustentabilidade e, a partir daí, começar a planejar e desenvolver estratégias para o desenvolvimento sustentável. No caso de estratégias econômicas, uma das mais faladas é a distribuição dos royalties sobre os minerais, que devem ser pagos em razão do caráter exaurível desses recursos naturais, uma vez não renovável, esses minérios são sujeitos a um custo, já que sua extração compromete futuras gerações.

Porém, o DNPM (2013) incide que as receitas da CFEM devam ser aplicadas em projetos que, direta ou indiretamente, revertam em prol da comunidade local, na forma de melhoria da infraestrutura, da qualidade ambiental, da saúde e da educação. Por sua vez, Enriquez (2007) expõe que na maioria dos grandes municípios mineradores, esse recurso, depois de entrar no caixa das prefeituras, é diluído nas despesas correntes, ficando assim difícil de desenvolver novas oportunidades de geração de emprego e renda, amenizando assim os efeitos da pobreza e da dependência excessiva da mineração.

Segundo Lamego (2002), a mineração é, em primeiro lugar e acima de tudo, uma atividade de risco e altamente competitivo no qual as empresas buscam os melhores e mais viáveis depósitos minerais. $\mathrm{O}$ impacto do desenvolvimento da mineração sobre os sistemas sócio-econômico e político é bastante amplo, sendo suas implicações sentidas muito além do tocante ao desempenho do setor.

A mineração só poderá almejar um desenvolvimento mais sustentável, ainda segundo Lamego (2002), se os lucros obtidos através do empobrecimento dos recursos minerais forem continuamente reinvestidos em outras formas de desenvolvimento econômico e social de caráter sustentável, visto que a sustentabilidade não é um conceito de fácil aplicação para esses recursos não renováveis.

Dessa forma, alguns autores se fazem presente mostrando que a mineração possa se enquadrar as questões sobre ser ou não sustentável. Para Vale (2002), não raramente, esse questionamento é encarado como uma heresia na medida em que a não renovabilidade dos bens minerais, por definição, comprometeria qualquer insinuação quanto à sustentabilidade do setor.

Segundo Barreto (2001), fica subtendido que a mineração, como atividade econômica, deve se comprometer, não só em buscar a maximização do uso dos recursos minerais sob o ponto de vista técnico e econômico, mas, sobretudo, contribuir para construção de um modelo de desenvolvimento econômico capaz de gerar condições de acumulação de capital e tecnologia e, ao mesmo tempo de assegurar a salubridade ambiental, de forma que, após a desativação e o fechamento de minas, o uso das áreas mineradas permita a contínua agregação de valores econômicos e sociais às comunidades locais e à sociedade. Ainda segundo Barreto (2001), em termos práticos, todas as atividades relacionadas à mineração - da pesquisa à lavra - deve prever:

*Os riscos e a proteção, dos impactos ambientais; *Monitoramento e a recuperação das áreas degradadas, de forma progressiva e contínua;

*Compartilhamento de benefícios econômicos com a sociedade nacional, em especial as comunidades locais;

*Uso futuro da área minerada;

*A máxima integração do projeto mineiro com o desenvolvimento das comunidades vizinhas.

Entretanto, o setor mineral é importante e constitui peça chave para o crescimento econômico e principalmente para o desenvolvimento de qualquer país, estado ou município. É claro que a potencialidade, produção e exportação de produtos minerais têm possibilitado, com força, a inserção do Brasil no cenário econômico internacional, bem como o seu cenário interno. Por outro lado, cresce também a preocupação com o aumento da extração mineral, sendo ela, uma atividade de alto potencial impactante sobre o meio ambiente, em especial sobre a biota, sobre o relevo, a qualidade das águas e sobre a população do seu entorno. Por se tratar de uma exploração de um recurso natural não-renovável, algumas considerações devem ser feitas quanto ao conceito de sustentabilidade econômica, social e ambiental da atividade.

Segundo Van Bellen (2005), a sustentabilidade econômica abrange alocação e distribuição eficiente dos recursos naturais dentro de uma escala apropriada. Trata-se do conceito de desenvolvimento sustentável, observado a partir da perspectivas econômica. Assim, os indicadores econômicos são essenciais para avaliar uma boa gestão e conseguentimente sua sustentabilidade. Para isso alguns autores se munem de alguns indicadores econômicos para melhor avaliar o desempenho ambiental do seu empreendimento, principalmente relacionados a questão mineral, (ver quadro 09). 
Quadro 09 - Indicadores Econômicos de Sustentabilidade para atividade Mineral

\begin{tabular}{|c|c|c|}
\hline \multicolumn{2}{|r|}{ Indicadores Econômicos } & Autores \\
\hline $\begin{array}{l}\text { Agregados } \\
\text { Selecionados }\end{array}$ & $\begin{array}{l}\text { ( Valor da produção; Faturamento; Margem Bruta; Aquisição de insumos locais e } \\
\text { externos; Geração de renda direta e indireta; Massas de salários e encargos; } \\
\text { Remuneração do capital; Impactos distributivo; Tributação direta e indireta; } \\
\text { Geração líquida de divisas; Prospecção e exploração; Pesquisa e } \\
\text { desenvolvimento(R\&D); investimentos em Infra-estrutura; Investimento em } \\
\text { Educação e Saúde; Investimento em expansão; Novos investimentos; } \\
\text { Investimentos em diversificação; Doações; Origem dos recursos. }\end{array}$ & $\begin{array}{l}\text { Lamego et al. } \\
(2002)\end{array}$ \\
\hline $\begin{array}{l}\text { Plano de } \\
\text { Fechamento de } \\
\text { mina }\end{array}$ & 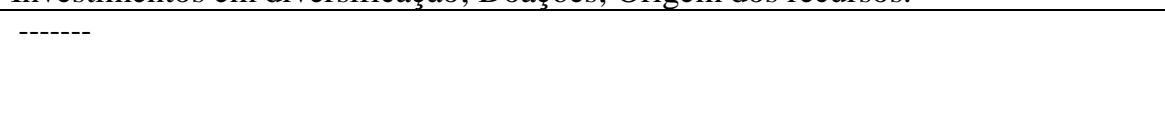 & $\begin{array}{l}\text { Lamego et al. } \\
(2002)\end{array}$ \\
\hline
\end{tabular}

Fonte: adaptado (Villas Bôas e Beinhoff, 2002)

Entre tantos indicadores que são usados pela indústria mineral em diferentes dimensões pra avaliar a sustentabilidade, alguns trabalhos explanam além das dimensões, econômicas, sociais e ambientais, outra que também se mostra importante e singular à atividade. Essa dimensão é introduzida pelos indicadores técnicos, que vem facilitar as informações sobre o desempenho técnico. É o caso de Pimiento (2005), que utiliza alguns desses indicadores como: Área total do projeto (área operacional; espessura da camada de cobertura; preenchimento de área; reservas disponíveis $\mathrm{m} 3$; vida útil do projeto (anos); produção aproximado $\mathrm{em}^{3}$ / ano).

No entanto, buscar harmonia entre ecossistema e economia não é tarefa fácil; menos ainda trata de buscar um indicador que possa medir a ação humana, responsável pelo consumo e poluição de nossos recursos naturais, levada por um aumento populacional e o crescimento econômico. Com isso suje como alternativa o uso de indicadores de sustentabilidade, principalmente para se trabalhar com um setor específico e tão intrínseco como o setor mineral. Entanto Villas Bôas (2009), afirma ser preciso elaborar indicadores de desenvolvimento sustentável que sirvam de base sólida para adotar decisões em todos os níveis e que contribuam para uma sustentabilidade autorregulada dos sistemas integrados do meio ambiente e o desenvolvimento.

- Segundo Gallopin apud Van Bellen (2005), indicadores devem ser meios de comunicação e toda forma de comunicação requer entendimento entre os participantes do processo. Por isso, os sistemas de indicadores devem ser os mais transparentes possíveis e seus usuários devem ser estimulados a compreender seu significado e sua significância dentro de seus próprios valores. Entretanto o autor ainda sugere que sistemas de indicadores de desenvolvimento sustentável devem seguir alguns requisitos universais: Os valores dos indicadores devem ser mensuráveis (ou observáveis);

- Deve existir disponibilidade dos dados;

- A metodologia para coleta e o processamento dos dados, bem como para a construção dos indicadores, deve ser limpa, transparente e padronizada;

- Os meios para construir e monitorar os indicadores devem estar disponíveis, incluindo capacidade financeira, humana e técnica;

- Os indicadores ou grupo de indicadores devem ser financeiramente viáveis; e

- Deve existir aceitação política dos indicadores no nível adequado; indicadores não-legitimados pelos tomadores de decisão são incapazes de influenciar as decisões.

Criar um índice onde os indicadores mostrem as dimensões econômicas, social e ambiental em um só é uma tarefa complicada, já que não temos como criar valores para contabilizar o bem estar social e o prejuízo causado ao ecossistema, deixando assim qualquer medida incoerente. Apesar de não poder misturar em um indicador não podemos separá-los para chegar à sustentabilidade. O que se percebe é que deve minimizar o fluxo de energia e matéria nas atividades humanas e desvincular avanços sociais 
de quantitativos de consumo, no entanto a obsessão pelo máximo produto nacional bruto o impede deste objetivo Van Bellen (2005).

\section{Dimensão Ambiental da Mineração}

Um dos grandes entraves da mineração são as questões ambientais. Apesar de se tratar de um recurso finito, ainda são poucas as alternativas de gerir o seu reuso, dada a imensidão de minerais existentes. Entretanto, para Barreto (2001), a mineração é considerada como atividade potencialmente poluidora do meio ambiente; desse modo, recebe um tratamento da gestão pública ambiental comum a todas as atividades que efetiva ou potencialmente degradam a qualidade do meio.

Segundo Barreto (2001), é considerado impacto ambiental: qualquer alteração das propriedades físicas, químicas e biológicas do meio ambiente, causada por qualquer forma de matéria ou energia resultante das atividades humanas que, direta ou indiretamente, afetem a saúde, a segurança e o bem estar da população; as atividades sociais e econômicas; a fauna e a flora; as condições estéticas e sanitárias do meio ambiente; e a qualificação dos recursos ambientais.

Os impactos ambientais da atividade mineral segundo Barreto (2001) são: alteração de lençol de água subterrânea, poluição sonora, visual, da água, ar e solo, impactos sobre a fauna e a flora, assoreamento erosão, mobilização da terra, instabilidade de taludes, encostas e terrenos em geral, lançamentos de fragmentos e vibrações.

Entretanto, todos esses impactos causados ao meio ambiente, são causados tanto pelas minas quantos as empresas de mineração, porém, é praticamente impossível para a sociedade industrial privar-se do uso dos recursos minerais. Uma vez que os múltiplos usos desses recursos possibilitam o grande desenvolvimento industrial dos dois últimos séculos ( Ross, 2005).

De acordo com a resolução do CONAMA 01, de 1986, considera impacto ambiental "qualquer alteração das propriedades físicas, químicas e biológicas do meio ambiente, causada por qualquer forma de matéria ou energia resultante das atividades humanas que, direta ou indiretamente, afetem a saúde, a segurança e o bem-estar da população; as atividades sociais e econômicas a fauna e a flora; as condições estéticas e sanitárias do meio ambiente; e a qualidade dos recursos ambientais".

Ainda referente a mesma resolução, sendo realizado através de estudos de impacto ambiental -EIA, que se constitui em um conjunto de atividades técnico-científicas destinadas à identificação, previsão e valoração dos impactos e à analise de alternativas. As conclusões do EIA devem ser apresentadas, de forma objetivas, no Relatório de Impacto Ambiental - RIMA, que deve ser elaborado por profissionais legalmente habilitados, em linguagem adequada á sua compreensão das comunidades afetadas.

Desta forma, Barreto (2001), ainda relata outro importante instrumento é o Plano de Controle Ambiental - PCA, que é o projeto executivo do conjunto de atividades técnicocientíficas destinadas a minimizar os impactos ambientais que venham a ser gerados por atividades econômicas, elaborado por profissionais legalmente habilitados.

Para tanto, é importante desenvolver estratégias de mitigação desses impactos, principalmente relacionadas a uma atividade de extração mineral essencial para o desenvolvimento de um determinado local ou município. Uma vez que a mesma seja a sua principal atividade econômica, não sendo bem explorada poderá ocasionar áreas de extrema degradação, impossibilitando a manutenção de um equilíbrio para que essas atividades consigam se perpetuar pelas futuras gerações.

Um dos passos a serem seguidos para tentar solucionar ou amenizar os impactos causados ao meio seria, de inicio, uma educação adequada ao minerador de acordo com as suas necessidades e relacioná-las ao importante processo de aprendizagem sobre a melhor forma de gerenciar um possível empreendimento, levando em conta, sobretudo, aspectos ambientais, econômicos, técnicos, culturais, sociais, trabalhistas, além de outros. Segundo Parizotto (1995), (...) “ a educação ambiental tem como principal objetivo a sensibilização, conscientização e mobilidade de todas as camadas da população para a conservação e preservação ambiental".

Dito de outro modo, seria administrar os recursos naturais de forma inteligente, de tal maneira que se tenha progresso sustentável com diminuição da agressão ao meio ambiente.

Outro ponto preocupante nas questões ambientais são as ações das empresas do setor mineral que não costumam envolver a preservação de um ecossistema ou a garantia de segurança da comunidade, desconsiderando também o bemestar humano e os direitos dos habitantes locais e, por fim, a qualidade de vida das atuais e futuras gerações. Os princípios de desenvolvimento sustentável demandam o crescimento econômico e a preservação ambiental desde o início de um projeto, incluindo a avaliação dos valores morais e 
éticos, considerando valores subjetivos da comunidade, ao invés de apenas enfatizar o tradicional valor econômico (Amade e Lima, 2009).

Viana (2012) já afirma que, apesar do caráter não renovável dos bens minerais, a mineração sustentável precisa promover a equidade intra e intergeracional de formas diferentes. $\mathrm{Na}$ perspectiva da geração atual, deve minimizar e compensar seus impactos ambientais negativos, sendo assim, equilibrar certos níveis de proteção ecológica e de padrões ambientais e garantir o bem-estar socioeconômico, dispondo de um crescimento e melhor distribuição de renda, melhoria das condições de educação e de saúde, diminuindo a pobreza, reduzindo a exclusão e aumentando o índice de emprego.

Nesse sentido, Azapagic (2004) argumenta que essas e outras questões levaram a indústria mineral a se envolver no debate sobre a sustentabilidade e, a partir daí, começar a planejar e a desenvolver estratégias para o desenvolvimento sustentável. O grande desafio que se coloca para o setor de mineração, assim como para os governos, é como desenvolver uma atividade de mineração sustentável, que garanta o atendimento das necessidades atuais, sem colocar em risco as necessidades das gerações futuras e, ao mesmo tempo, proteger o meio ambiente.

Entretanto, Barreto (2001), afirma que embora todos os projetos, independente de sua magnitude, devam ser previamente aprovados, a existência de garimpeiros, cooperativas, pequenos mineradores, bem como de alguns médios produtores, que detêm baixo conhecimento tecnológico e a falta de disponibilidade de recursos econômicos ou de acesso a fontes de financiamento sugerem que essas novas estruturas de governo dêem o suporte necessário na área ambiental para a sobrevivência dessas atividades, especialmente nas áreas técnica e legal, inclusive trazendo benefícios para a sociedade em geral, como a perspectiva de promoção social e minimização dos custos de matérias-primas (ex: materiais de construção). Salienta que esses setores representam a metade da economia mineral e é a maior fonte de trabalho do setor.

Algumas ações relevantes para a sustentabilidade, segundo Barreto op cit:

Apesar das ações acima citadas terem se iniciado nas esferas maiores de produção, nas maiorias das pequenas minerações a realidade se resume distante desta. A sustentabilidade não é algo a ser atingido, mas um processo contínuo; no entanto, um pré-requisito pra a formulação de uma política relativa à sustentabilidade é uma visão de estado e mundo em direção ao qual desejamos avançar. Portanto, a formulação de políticas para a sustentabilidade requer o uso da imaginação para definir um futuro promissor, que possa considerar como meta políticas criativas preocupadas com o longo prazo.

Entretanto, na atividade mineral, ainda são tímidas as ações ambientais, sobretudo no que tange as questões de sustentabilidade, visto tratar-se de atividade de recursos naturais finitos, fato que, dificulta o entendimento da mesma poder um dia mostrar-se sustentável. O setor mineral como um todo ainda goza de poucos trabalhos científicos, que possibilitem alternativas de gestão ambiental ligadas ao desenvolvimento sustentável.

A dimensão social para a Sustentabilidade mineral

A sustentabilidade pode ser entendida grosso modo como o desenvolvimento de uma atividade em maior equilíbrio. Um bom desempenho das atividades realizadas pelas empresas para maximizar os benefícios dos projetos no âmbito social, ao mesmo tempo em que, minimizam seus impactos, estende-se muito além do que é exigido pelas leis dos países em que operam. Neste contexto, o termo "social" não se refere aos problemas sociais, mas aos objetivos sociais, tais como o desenvolvimento econômico, contribuições sociais e de proteção ambiental (Villas Bôas, 2011).

Para Van Bellen (2005), na sustentabilidade observada da perspectiva social, a ênfase é dada à presença do ser humano na ecosfera. A preocupação maior é com o bem-estar humano, a condição humana e os meios utilizados para aumentar a qualidade de vida dessa condição.

Uma das preocupações em relação ao meio mineiro ocorre em relação à saúde e à segurança do trabalhador. Esses são dois aspectos muito debatidos atualmente, haja vista que se trata de uma atividade de alta periculosidade. Viana (2012) ressalta que até meados da segunda metade do século anterior a falta de equipamentos de proteção individual (EPI) causava um alto nível de acidentes de trabalho nas minas legalizadas e, principalmente, nas extrações clandestinas. Essa realidade responde ainda nos dias atuais por significativos passivos sociais trabalhista.

Essa situação, que se atrela no que tange aos aspectos socioeconômicos, é parcialmente condicionada pela situação econômica da região, pelo perfil das comunidades existentes no entorno e pelo grau de dependência delas em relação à mineração. 
Quadro 03: Alternativas para um bom desempenho da Mineração

\begin{tabular}{|c|c|c|}
\hline \multicolumn{3}{|c|}{ Alternativas para o bom desempenho da Atividade Mineral } \\
\hline $\begin{array}{l}\text { Buscar atuar sempre de forma a } \\
\text { prevenir a degradação ambiental; }\end{array}$ & $\begin{array}{l}\text { Minimizar ao máximo os } \\
\text { impactos, buscando, sempre que } \\
\text { possível, a condição mais próxima } \\
\text { do natural de origem dos terrenos } \\
\text { trabalhados; }\end{array}$ & $\begin{array}{l}\text { Restaurar satisfatoriamente os sítios } \\
\text { degradados; }\end{array}$ \\
\hline $\begin{array}{l}\text { Controlar os processos erosivos e } \\
\text { de estabilidade do terreno; }\end{array}$ & $\begin{array}{l}\text { Reduzir a geração de resíduos e } \\
\text { rejeitos descartados; }\end{array}$ & $\begin{array}{l}\text { Reaproveitar ao máximo os rejeitos } \\
\text { primários, os resíduos, as escórias e as } \\
\text { areias de fundição; }\end{array}$ \\
\hline $\begin{array}{l}\text { Reutilizar, reciclar e buscar novos } \\
\text { usos para os minerais; }\end{array}$ & $\begin{array}{l}\text { Promover a deposição segura, em } \\
\text { especial dos resíduos perigosos, } \\
\text { mantendo sua estabilidade, e } \\
\text { efetuar o monitoramento contínuo; }\end{array}$ & $\begin{array}{l}\text { Reduzir as drenagens ácidas desde o } \\
\text { início do projeto até sua total } \\
\text { estabilização, dentro de padrões } \\
\text { aceitáveis; }\end{array}$ \\
\hline $\begin{array}{l}\text { Garantir a segurança e } \\
\text { estabilidade física, química } \\
\text { biológica das áreas mineradas } \\
\text { edjacentes; }\end{array}$ & $\begin{array}{l}\text { Revegetar de forma contínua as } \\
\text { áreas desmatadas e outras } \\
\text { adjacentes ao projeto; }\end{array}$ & $\begin{array}{l}\text { Utilizar nos processos, de forma } \\
\text { eficiente, a energia, a água, e as } \\
\text { substâncias químicas; }\end{array}$ \\
\hline $\begin{array}{l}\text { Assegurar que a atividade mineira } \\
\text { não represente ameaça para a } \\
\text { qualidade das águas; }\end{array}$ & $\begin{array}{l}\text { Prever um plano de gerenciamento } \\
\text { dos recursos hídricos; }\end{array}$ & $\begin{array}{l}\text { Proteger as águas superficiais e } \\
\text { subterrâneas; }\end{array}$ \\
\hline $\begin{array}{l}\text { Gerenciar e monitorar de forma } \\
\text { contínua todas as áreas de } \\
\text { influência do projeto mineiro; }\end{array}$ & $\begin{array}{l}\text { Reduzir a níveis satisfatórios de } \\
\text { emissão de poeiras e gases na } \\
\text { atmosfera; }\end{array}$ & Minimizar os impactos visuais; \\
\hline $\begin{array}{l}\text { Garantir a segurança, a saúde e a } \\
\text { higiene da comunidade e das áreas } \\
\text { públicas; }\end{array}$ & $\begin{array}{l}\text { Promover e manter a auto- } \\
\text { sustentabilidade dos ecossistemas, } \\
\text { bem como sua biodiversidade, } \\
\text { protegendo a vida e os espécimes } \\
\text { da fauna e da flora; }\end{array}$ & $\begin{array}{l}\text { Prever o desmonte e a remoção das } \\
\text { instalações, equipamentos e materiais; }\end{array}$ \\
\hline $\begin{array}{l}\text { Executar a limpeza e a } \\
\text { revitalização das áreas industriais; }\end{array}$ & $\begin{array}{l}\text { Manter um canal de informação } \\
\text { permanente com a comunidade } \\
\text { local sobre as atividades de rotina, } \\
\text { os possíveis riscos, e treinamento } \\
\text { de emergência, quando for o caso; }\end{array}$ & $\begin{array}{l}\text { Assegurar o uso viável da terra e a } \\
\text { qualidade de vida da comunidade local } \\
\text { após a atividade de mineração; }\end{array}$ \\
\hline $\begin{array}{l}\text { Estabelecer cronograma físico- } \\
\text { financeiro para todas as etapas do } \\
\text { projeto; }\end{array}$ & $\begin{array}{l}\text { Prever medidas complementares e } \\
\text { corretivas após a exaustão da } \\
\text { mina; }\end{array}$ & $\begin{array}{l}\text { Promover medidas compensatórias como } \\
\text { forma de amenizar os impactos } \\
\text { relevantes. }\end{array}$ \\
\hline $\begin{array}{l}\text { Algumas ações de governo em } \\
\text { curso no Brasil: }\end{array}$ & Modernizar a legislação vigente; & $\begin{array}{l}\text { Harmonizar as normas e procedimentos } \\
\text { nas diversas unidades da federação; }\end{array}$ \\
\hline $\begin{array}{l}\text { Articular os órgãos governamentais } \\
\text { em suas diversas esferas; }\end{array}$ & $\begin{array}{l}\text { Intensificar o diálogo entre } \\
\text { governo, indústria mineral e } \\
\text { sociedade civil (comunidades } \\
\text { locais e ONG); }\end{array}$ & $\begin{array}{l}\text { Promover incentivos e formas de } \\
\text { compensação para os projetos mineiros } \\
\text { auto-sustentáveis. }\end{array}$ \\
\hline $\begin{array}{l}\text { Criar mecanismos de } r \text { suporte } \\
\text { técnico e econômico para as } \\
\text { garantias ambientais; }\end{array}$ & $\begin{array}{l}\text { Promover a captação de recursos } \\
\text { destinados aos projetos ambientais } \\
\text { no setor. }\end{array}$ & \\
\hline
\end{tabular}

Fonte: Adaptado, Barreto (2001).

Desta forma, é possível, segundo Villas Bôas (2011), ainda enfatizar que a responsabilidade social empresarial (RSE) implica conciliar o interesse das partes interessadas direta $\mathrm{e}$ indiretamente à empresa e, por outro, incorporar elementos de governança corporativa, tais como: transparência; ética; retornos sobre o capital; programas sociais e aplicação das normas trabalhistas, ambientais e outras que compõem o seu compromisso ético com a sociedade.

Entretanto, Viana (2012) enfatiza que a responsabilidade social coorporativa ou sustentabilidade coorporativa é o comprometimento da empresa em contribuir para o desenvolvimento sustentável, trabalhando com os empregados e suas famílias, as comunidades 
locais e a sociedade em geral para a melhoria da qualidade de vida. De modo que esses benefícios possam ir além da fase de exaustão das jazidas, garantindo assim alternativas produtivas locais para etapas futuras.

O olhar social dentro das corporações minerais vem ganhando cada vez mais espaço e dando origem a padrões que auxiliam a medição de desempenho em suas responsabilidades sociais. Diversas propostas e iniciativas estão sendo realizadas por organizações internacionais (ver quadro 02).

Quadro 04 - Propostas e iniciativas de organizações internacionais sobre responsabilidade social.

\begin{tabular}{|l|l|}
\hline \multicolumn{4}{|c|}{ Organizações Internacionais e Responsabilidade Social } \\
\hline Normas OHSAS 18001 & $\begin{array}{l}\text { Para a certificação de Sistemas de Gestão de } \\
\text { Segurança e Saúde Ocupacional. }\end{array}$ \\
\hline Social Accountability 8000 (AS 8000) & $\begin{array}{l}\text { Desenvolvido pelo Council on Economic Priorities } \\
\text { Acreditation Agency, para acompanhar e verificar as } \\
\text { condições de trabalho. }\end{array}$ \\
\hline Domini 400 Social index (DSI 400) & $\begin{array}{l}\text { Índice de ações que reúne empresas com } \\
\text { investimentos socialmente responsáveis. }\end{array}$ \\
\hline Índice FTSE4Good & $\begin{array}{l}\text { Que inclui as empresas que atendam SRI } \\
\text { (Investimentos Socialmente Responsáveis). }\end{array}$ \\
\hline Norma ISSO 26000 & $\begin{array}{l}\text { De responsabilidade social Coorporativa Gestão } \\
\text { atualmente em desenvolvimento. }\end{array}$ \\
\hline BS 8800 & $\begin{array}{l}\text { A certificação dos sistemas de saúde e de segurança } \\
\text { nas empresas. }\end{array}$ \\
\hline
\end{tabular}

Fonte: Adaptado, Villas Bôas (2011).

É bom salientar que os projetos sociais só serão de fato implementados quando houver um aumento da consciência, principalmente pelas partes envolvidas da empresa. Entretanto, VillasBôas (2011), afirma que os projetos dependem exclusivamente das empresas (a determinação dos valores, dos projetos e ações). Não há um sistema de regulamentação que discipline as ações das empresas (ao contrário do meio ambiente). A falta de regulamentação afeta diretamente as comunidades locais, uma vez que os diferentes projetos realizados pelas empresas de mineração nem sempre contribuem ou promovem $\mathrm{o}$ desenvolvimento social e econômico. Tanto que vários projetos do campo social acabam bem antes de começarem a ter realmente resultados, por falta de políticas de acompanhamento ou fiscalização.

Entretanto, autores como Fernandes et al. (2011) apontam para a dimensão social como sendo vínculos de confiança, de coesão social, de participação e de compartilhamento de projetos, construídos a partir da relação que se estabelece entre o empreendimento mineiro e a sociedade como um todo; inclusive, com o poder público. A costura dessa relação é apontada como de fundamental importância para o estabelecimento de estratégias construtivas em prol da sustentabilidade na perspectiva social em territórios mineradores. Além disso, a sustentabilidade social requer garantias de avanço nas condições de saúde, educação, segurança pública e demais direitos sociais fundamentais.
$\mathrm{O}$ autor supracitado ainda acrescenta que essa dimensão da sustentabilidade é reiteradamente negligenciada na maior parte dos casos de construção de uma base social propícia ao estabelecimento de relações sinérgicas entre agentes do estado e membros da sociedade civil, a exemplo da deficiência das ações de comunicação social por parte da empresa; violação de direitos humanos; desarticulação das comunidades atingidas ligadas às negociações individuais e não coletivas; baixa coesão social ligada ao processo inicial de aquisição de terras; sensação de insegurança ligada à fragmentação do processo de licenciamento que se arrasta há anos, tornando-se o empreendimento minerário inegociável. Além de marginalização dos atingidos, ligada à falsa culpa impetrada por terceiros, pelo atraso do processo de licenciamento do empreendimento, entre outros.

Estudos concluíram que projetos encaminhados dessa forma se revelam catalisadores de conflitos e situações de injustiça socioambiental, nas quais pequenos grupos de empresários auferem fabulosos benefícios, enquanto as populações mais vulneráveis sofrem com os impactos negativos das externalidades do empreendimento econômico (Fernandes et al., 2011)

Nesse sentido, algumas pesquisas se destacam seus indicadores no campo social, argumentando a necessidade de incorporação de novas técnicas para o processo de 
desenvolvimento sustentável, vejamos alguns deles:

Quadro 05- Indicadores de Sustentabilidades Social para atividade Mineral

\begin{tabular}{|c|c|c|}
\hline \multicolumn{2}{|r|}{ Indicadores Sociais } & Autor \\
\hline Emprego & $\begin{array}{l}\text { ( total de empregos diretos; total de empregos indiretos; Empregos gerados por } \\
\text { unidade de produto; remuneração mínima/Salário mínimo(\%); Remuneração } \\
\text { Média/ Salário mínimo }(\%) \text {; Subcontratação e Tercerização; Monitoramento das } \\
\text { condições oferecidas pelos subcontratados; Perfil da força de trabalho: feminino, } \\
\text { minorias etc; Condições de salubridade e segurança; Iniciativas direcionadas a } \\
\text { saúde e segurança do trabalhador; acidentes de trabalho(H/Hora); Greves e } \\
\text { paralizações (dias); Multas e penalidades; Programa de treinamento e } \\
\text { Educação(\$/trabalhador); Programa de Saúde e previdência(\$/trabalhador); níveis } \\
\text { de satisfação da força de trabalho; Canais de comunicação e participação no } \\
\text { processo decisório. }\end{array}$ & $\begin{array}{l}\text { Lamego et } \\
\text { al. (2002) }\end{array}$ \\
\hline $\begin{array}{l}\text { Relações com } \\
\text { a Comunidade }\end{array}$ & $\begin{array}{l}\text { (Empregos diretos gerados; Empregos indiretos gerados; Empregos gerados por } \\
\text { unidade de produto; Gastos junto à Comunidade }(\%) \text {; Subcontratação e tercerização } \\
\text { junto à comunidade }(\%) \text {; Disponibilização da infra-estrutura social do Emprego; } \\
\text { Criação de infra-estrutura social na região(\$); Níveis de integração com a } \\
\text { comunidade; Programas de capacitação e educação }(\%) \text {; Integração com o sistema } \\
\text { de defesa civil e saúde pública; Ocorrências e atritos com a comunidade; Reclamos } \\
\text { e manifestações públicas; Níveis de satisfação da comunidade; Canais de } \\
\text { comunicação e participação no processo decisórios. }\end{array}$ & $\begin{array}{l}\text { Lamego et } \\
\text { al. }(2002)\end{array}$ \\
\hline
\end{tabular}

Fonte: Adaptado (Villas Bôas e Beinhoff, 2002)

Ao discutir a construção de uma forma de desenvolvimento mais sustentável vinculado ao setor de mineração, verifica-se uma necessidade premente de se dispor de indicadores de sustentabilidade, como mostra o quadro acima, e ferramentas de apoio específicas que de alguma forma reduzam a subjetividade inerente ao tema, bem como a partir de sua mensuração proporcione uma análise e acompanhamento das interferências ocasionadas pela execução dessa atividade no processo de desenvolvimento de uma determinada região e/ou município.

\section{Indicadores de sustentabilidade para uma mineração sustentável}

Segundo Barreto (2001), a mineração embora sendo uma das primeiras atividades impulsionadas pela centelha do gênio humano, tem sido uma das menos aceitas dentro do novo arcabouço conceitual do desenvolvimento sustentável (DS). A razão disso é que, desde sua formulação inicial pela comissão Brundtland, esse conceito vem sendo progressivamente relativizado por diferentes interpretações, a depender do objetivo a que se destina.

Para isso, a elaboração dos indicadores de sustentabilidade para o setor de mineração deve levar em consideração as dimensões do desenvolvimento sustentável e incluir três aspectos essenciais: o econômico, o social e o ambiental, vistos sob uma perspectiva integrada, para dar uma visão mais concreta da relação homem-meio ambiente, inserida no contexto da empresa de mineração.

Os indicadores de sustentabilidade ocupam papel central, pois podem ser usados como ferramentas de mobilização das partes interessadas na análise e avaliação de sustentabilidade da atividade, bem como nos processos de educação e comunicação (Malheiros, et al., 2012).

Segundo o autor supracitado, outro desafio a ser trabalhado é a viabilização de sistema de indicadores para diferentes escalas de gestão - do local ao global. Esses sistemas devem individualmente atender especificidades locais, captando esforços e medindo desempenho de cada unidade. Ao mesmo tempo, é preciso identificar indicadores que possam comparar as unidades, criando uma nova unidade de análise - regional ou global. Nessa nova escala de análise, outros aspectos podem surgir como fundamentais, tais como fatores cumulativos de pressão sobre os recursos naturais, fragmentação de ecossistemas, capacidade de suporte, serviços ecossistêmicos, migração, redes de cidades, globalização, entre outros.

Também os indicadores constituem um modelo da realidade, uma forma de representá-la, eles não são a realidade em si, mas pode-se dizer que representam uma pequena parte dela. Porém, é uma forma de se buscar soluções simples, com 
base nos mesmos indicadores, para questões complexas da realidade. Se, contudo, a mineração só tem importância local, então, indicadores locais são mais apropriados. Em última instância, não há um conjunto de indicadores de sustentabilidade que seja único, perfeito e universalmente apropriado. Além disso, a transparência, a participação social e o diálogo com os diferentes atores envolvidos em qualquer atividade, como na mineraria, são princípios-chave (Villas-Bôas, 2005).

Para Mitchell (1996), indicador é uma ferramenta que permite a obtenção de informações sobre uma dada realidade. Os indicadores comumente utilizados, como o produto Nacional Bruto (PNB) ou as medições das correntes individuais de contaminação ou de recursos, não dão indicações precisas de sustentabilidade. Os métodos de avaliação da interação entre diversos parâmetros setoriais do meio ambiente e o desenvolvimento são imperfeitos ou se aplicam deficientemente. No entanto, Villas Bôas (2009) afirma ser preciso elaborar indicadores de desenvolvimento sustentável que sirvam de base sólida para adotar decisões em todos os níveis e que contribuam para uma sustentabilidade autorregulada dos sistemas integrados do meio ambiente e o desenvolvimento.

Indicadores são capazes de transmitir o conhecimento de forma simplificada de algo relevante para a sociedade, sendo imprescindível como fonte de informações para a gestão ambiental das cidades. Os indicadores de sustentabilidade refletem se um dado local possui ou não características ambientais desejáveis, por isso são necessários durante $\mathrm{o}$ processo de avaliação ambiental; sobretudo, em relação aos recursos minerais. Estudos avançaram em função da necessidade de se definir padrões sustentáveis de desenvolvimento que considerassem aspectos ambientais, econômicos, sociais, éticos e culturais.

Para Bossel apud Van Bellen (2005), a maioria dos indicadores relacionados à sustentabilidade não possui um sistema teórico conceitual que reflita a viabilidade e a operação do sistema total; eles normalmente refletem a experiência e os interesses de pesquisa dos especialistas. Por isso, são por vezes extremamente densos em algumas áreas e esparsos ou inexistentes em outras igualmente importantes. Os indicadores desse tipo não são sistemáticos e não refletem as interações entre sociedade e meio ambiente no sistema total.

Segundo Villas Bôas (2005), em mineração, os indicadores constituem uma espécie de guia de reconhecimento dos recursos existentes, das opções, de suas vantagens, comercialização, relações com o ambiente natural e interação com os meios sociais. Todos esses parâmetros são governados por indicadores específicos que dão a conhecer o impacto generalizado da atividade mineira sobre o meio ambiente e a comunidade.

$\mathrm{Na}$ mineração, as profundas diferenças de porte, substâncias extraídas e impactos econômicos, sociais e ambientais dificultam a escolha de um conjunto único de indicadores de sustentabilidade, bem como sua construção para acompanhar todas as fases da atividade extrativa mineral (Villas Bôas, 2011).

Contudo, vários sistemas foram criados na atualidade para que aponte possibilidades de um desenvolvimento mais sustentável para uma atividade altamente degradante e impactante ao meio em que se insere como mostra abaixo (quadro 05).

Estes Sistemas buscam mensurar a sustentabilidade e trazem importantes contribuições conceituais e metodológicas. No entanto, todos apresentam peculiaridades, tais como: números de indicadores, critérios de seleção e análises, como também parâmetros de análises e formas de aplicação da população que se encontra inserida no contexto.

Dessa forma, apesar de haver indicadores propostos para a atividade mineral, sempre haverá alguma área ou algum espaço que não será atingido. Esses sistemas sempre serão limitados a determinados pontos para que se tenha uma maior precisão dos dados. No caso de se avaliar uma determinada extração mineral, por que não avaliar toda a área em que se insere a mesma? Sendo assim, avaliar também o município onde se insere a atividade de extração mineral explana uma forma mais concreta do espaço e da sua atividade econômica, no caso de municípios que tenham como principal atividade econômica a extração mineral.

Para tanto, inserir um índice a uma atividade econômica e não fazer a investigação de toda a área onde se insere, formula uma investigação um tanto frágil do ponto de vista sustentável. Incluir a participação municipal, através de índices que também possam fazer essa averiguação, seria um quanto necessário, principalmente quando se avalia uma atividade altamente degradante e dependente da esfera municipal.

Além de todos esses entraves, os municípios ainda se deparam com a dicotomia da atividade econômica essencial para o seu desenvolvimento e a gama de conflitos gerados pela mesma, quando 
se trata de uma atividade degradante para o meio ambiente e social onde se insere.

\section{Sustentabilidade municipal}

Segundo Vasconcellos (2002), após a Constituição de 1988, os municípios começaram a ter mais controle sobre questões ambientais locais. Inclusive, a implementação das leis Orgânicas Municipais, dos Planos Diretores e da nova legislação municipal específica sobre as questões relativas ao meio ambiente foram elaboradas e estão sendo implementadas de forma heterogênea, de acordo com as variadas realidades municipais.

Surgem, a partir da década de 90, os primeiros indicadores de desenvolvimento, o IDH
- Índice de Desenvolvimento Humano, bastante conhecido nacionalmente e composto por apenas quatro indicadores. Posteriormente, em 1998, registra-se a elaboração do IDH-M, ou seja, o IDH a nível municipal, calculado para dimensionar o desenvolvimento humano na totalidade dos municípios brasileiro, segundo Nahas (2006). Porém, a autora ressalta que, desde 1995, já se produziam outros índices que permitiam também comparar condições de vida dos municípios, como o Índice Social, que compara os 187 maiores municípios brasileiros e o Índice Social Municipal, que permitiu comparar os maiores municípios do estado de São Paulo.

Quadro 05 - Sistema de indicadores utilizados na Atividade Mineral

\begin{tabular}{|c|c|c|}
\hline $\begin{array}{c}\text { Sistemas de Indicadores } \\
\text { utilizados na Atividade } \\
\text { Mineral }\end{array}$ & Abordagens & Aplicações \\
\hline $\begin{array}{l}\text { Índice Global de } \\
\text { Sustentabilidade (IGS) }\end{array}$ & $\begin{array}{l}\text { Para obtenção do indicador de sustentabilidade denominado de } \\
\text { Índice Global de Sustentabilidade (IGS), desenvolve-se um } \\
\text { "Checklist" com respostas sim ou não a uma série de questões, } \\
\text { que, embora simples, são relativas a ações-chave da atividade de } \\
\text { mineração (González; Carvajal, 2002). }\end{array}$ & $\begin{array}{l}\text { Granda et al. } \\
\text { (2006); } \\
\text { Gonzáles et al. } \\
\quad(2002)\end{array}$ \\
\hline $\begin{array}{l}\text { Pressão/Estado/Impacto/ } \\
\text { Resposta - PEIR }\end{array}$ & $\begin{array}{l}\text { Desenvolvido pela Organização para Cooperação e } \\
\text { Desenvolvimento Econômico (OCDE, 1993), Inicialmente, a } \\
\text { proposta da matriz Pressão/Estado/Resposta - PER era fornecer } \\
\text { mecanismos para o monitoramento do progresso ambiental para } \\
\text { os países que fazem parte da instituição, com grande importância } \\
\text { internacional (van berkel, 2000). Em 1995, o Programa das } \\
\text { Nações Unidas para o Meio Ambiente (PNUMA) aprimorou o } \\
\text { modelo PER, acrescentando o elemento Impacto (que reflete os } \\
\text { efeitos do estado do meio ambiente) e formulando a matriz PEIR. }\end{array}$ & $\begin{array}{l}\text { Ferreira et al. } \\
\quad(2010)\end{array}$ \\
\hline $\begin{array}{l}\text { Indicadores de } \\
\text { desenvolvimento } \\
\text { sustentável para a } \\
\text { indústria extrativa } \\
\text { mineral - }\end{array}$ & $\begin{array}{l}\text { Esse sistema de indicador para indústria extrativa mineral surge } \\
\text { como proposta significativa ao Desenvolvimento Sustentável, } \\
\text { uma vez que o mesmo é construído de acordo com a realidade } \\
\text { local. Ou seja, para cada indústria existem seus indicadores. } \\
\text { Sendo assim, para a construção desses indicadores haverá sempre } \\
\text { a participação da comunidade onde se insere a pesquisa, os } \\
\text { conhecidos "stakeholders, partes interessadas pela mesma, } \\
\text { podendo responder no seu início a perguntas-chave que darão } \\
\text { ênfase à construção dos indicadores: "O que eu sei?; O que eu } \\
\text { tenho? E, por fim, O que eu quero?". Dessa forma, estes } \\
\text { indicadores serão fundamentais para que possam dinamizar o } \\
\text { processo, e que não se tenha dúvidas sobre a construção. }\end{array}$ & $\begin{array}{l}\text { Villas Bôas } \\
\text { (2005) }\end{array}$ \\
\hline $\begin{array}{c}\text { Índice de } \\
\text { Sustentabilidade da } \\
\text { Mineração - ISM }\end{array}$ & $\begin{array}{l}\text { Posposto por Viana (2012), o Índice de Sustentabilidade da } \\
\text { Mineração - ISM é aplicado em unidades operacionais } \\
\text { minerarias, incluindo o meio ambiente, as comunidades existentes } \\
\text { em seu entorno e o município em que elas se inserem. É } \\
\text { composto por } 70 \text { indicadores, sendo } 30 \text { ambientais, } 20 \text { sociais e } \\
20 \text { econômicos. }\end{array}$ & $\begin{array}{c}\text { Dantas;Freitas } \\
\text { (2014) }\end{array}$ \\
\hline
\end{tabular}

Fonte: Elaboração Própria.

Esses índices de sustentabilidade municipal foram surgindo e dinamizando o processo de avaliação do desenvolvimento sustentável, principalmente dos municípios, mostrando assim os rumos que a sociedade vem tomando em relação a sua interação com o meio ambiente natural. 
Neste sentido, conceitos relacionados a sustentabilidade, principalmente municipal, podem variar de lugar para lugar. Não necessariamente o que seria sustentável para uma cidade grande, seria também para um pequeno município. Segundo Jara (1998), a sustentabilidade significa, ou pode ter um significado dinâmico e flexível, principalmente pleiteado no respeito à vida. Todavia, o autor ainda afirma que a redução da pobreza, a satisfação das necessidades básicas, a conscientização da população, o resgate da equidade e o estabelecimento de uma forma de governo que garanta a participação social nas decisões são condições essenciais para que o processo de desenvolvimento seja julgado como sustentável.

Além disso, ainda segundo Jara (1998), para concretizar o desenvolvimento sustentável são imprescindíveis, além da modernização da institucionalidade estadual e municipal, a mobilização da sociedade, a redefinição dos papéis da mídia, a formação dos recursos humanos, novos instrumentos técnicos e sistema de informação que concorram para orientar as decisões, os mecanismos flexíveis de financiamento, a abertura democrática, o fortalecimento dos sistemas de parcerias entre atores públicos e privados.

Braga et al. (2004), afirma que um município é considerado mais ou menos sustentável à medida que é capaz de manter ou melhorar a saúde de seu sistema ambiental, minorar a degradação e o impacto antrópico reduzir as desigualdades sociais e prover os habitantes de condições básicas de vida bem como de um ambiente construído de forma saudável e segura, e ainda de construir pactos políticos que permitam enfrentar desafios presentes e futuros. $\mathrm{O}$ autor ainda acrescenta que no final da década de 1980 houve o surgimento de propostas de construção de indicadores ambientais. Tais propostas possuem em comum o objetivo de fornecer subsídio à formulação de políticas nacionais e acordos internacionais, bem como estimular a tomada de decisão por atores públicos e privados. Também buscam a interação entre a atividade antrópica e o meio ambiente, vivenciando o conceito de sustentabilidade em sua amplitude.

Segundo Araújo e Candido (2014), uma cidade para ser considerada sustentável tem que ser, antes de tudo, "democrática e justa". Os autores justificam que é aquela que atende às necessidades urbanas básicas da população, sobretudo as relacionadas à infraestrutura urbana.
Assim, devem ser observada, em sua organização e dinâmica, as diversas dimensões: social, econômica, institucional, ambiental/ecológica, cultural, política e territorial, possibilitando oferecer aos seus habitantes uma boa qualidade de vida.

Para que os municípios consigam ter suas ações pleiteadas dentro desse quadro, é preciso que comecem a replanejar suas ações, principalmente nas questões de ordem econômica; como suas principais atividades econômicas, pois através delas é que surgirão os primeiros passos para querer propor uma forma de desenvolvimento mais sustentável. Mudando então a forma de pensar, principalmente por pressões externas, como também a forma de agir. É nesse pensamento que são difundidas as ações de cunho sustentável, pois os municípios hoje são praticamente obrigados a melhorar seus índices, até mesmo por pressões do próprio governo.

Neste sentido, surgem os índices de sustentabilidade municipal como alternativa de mensuração das dimensões da sustentabilidade em nível local, agregando também as possibilidades de atender as peculiaridades de cada sistema, estabelecendo, assim, uma visão mais nítida de todo o processo para chegar à sustentabilidade, como ilustra o Quadro 05.

Alguns indicadores que fazem parte desses índices acima citados podem ser utilizados não apenas para avaliação comparativa dos mesmos, mas para expor a real situação muitas vezes não vista de problemas relacionados ao desenvolvimento da gestão municipal.

Esses índices foram surgindo $\mathrm{e}$ dinamizando o processo de crescimento sustentável, principalmente para os municípios, mostrando os rumos que a sociedade vem tomando em relação a sua interação com o meio ambiente natural e despertando assim para a importância de analisar seus indicadores. Porém, Van Bellen (2005) mostra que os indicadores devem ser entendidos como variáveis, ou seja, a representação operacional de um atributo (qualidade, característica, propriedade) de um sistema, tendo como principal objetivo agregar e quantificar informações ressaltando sua significância, de modo a melhorar o processo de comunicação e entendimento de fenômenos complexos.

A dinâmica da sustentabilidade, apesar de ser envolvida em diversos âmbitos na sua estratégia local ou municipal, distingue-se por indicadores bem específicos; porém, um tanto dinâmicos, dependendo da teoria ou sistema a ser analisado. 
A grande questão é saber como um município pode se mostrar sustentável, caso sua principal atividade econômica não se desenvolva de forma sustentável.

Madureira (2005) insiste que, sendo as cidades as maiores consumidoras de recursos naturais e simultaneamente as maiores produtoras de poluição e resíduos, surge como uma evidência que grande parte dos entraves à sustentabilidade ambiental global terá que ser resolvida em escala urbana. Entretanto, para que os municípios consigam ter suas ações pautadas nesse quadro é preciso, que comecem a planejar suas ações, principalmente nas questões de ordem econômica, pois será através delas que surgirão os primeiros passos para querer propor um desenvolvimento mais sustentável.

Quadro 05: Índices de Sustentabilidade para municípios

\begin{tabular}{|c|c|c|c|}
\hline Índices & Dimensões & Aplicação & Autor/ano \\
\hline $\begin{array}{l}\text { IQIM - Índice de } \\
\text { qualidade institucional } \\
\text { municipal }\end{array}$ & $\begin{array}{l}\text { Grau de participação, } \\
\text { Grau de capacidade } \\
\text { financeira e capacidade } \\
\text { de gerenciamento. }\end{array}$ & $\begin{array}{l}\text { Indicadores sociais sintéticos no } \\
\text { planejamento de políticas públicas - } \\
\text { O índice de qualidade institucional } \\
\text { dos municípios (IQIM) e o índice do } \\
\text { potencial de desenvolvimento do } \\
\text { município (IPDM) }\end{array}$ & $\begin{array}{l}\text { Fernandes e Sauer } \\
(2011)\end{array}$ \\
\hline $\begin{array}{l}\text { IDSM - índice } \\
\text { desenvolvimento } \\
\text { sustentável para os } \\
\text { municípios }\end{array}$ & $\begin{array}{l}\text { Social, demográfica, } \\
\text { econômica, política - } \\
\text { institucional, ambiental } \\
\text { e cultural }\end{array}$ & $\begin{array}{l}\text { Índice de } \\
\text { sustentável municipal (IDS-M): Uma } \\
\text { aplicação nos municípios que } \\
\text { compõem a sub bacia do médio } \\
\text { Pinharas no estado da Paraíba. }\end{array}$ & $\begin{array}{l}\text { Sales, Cândido e } \\
\text { Sales (2012) }\end{array}$ \\
\hline $\begin{array}{l}\text { IDSMP - Índice de } \\
\text { sustentabilidade } \\
\text { municipal }\end{array}$ & $\begin{array}{l}\text { Econômica, ambiental, } \\
\text { cultural, } \\
\text { institucional, solítico- } \\
\text { demográfico. }\end{array}$ & $\begin{array}{l}\text { Índice de desenvolvimento } \\
\text { sustentável municipal participativo: } \\
\text { uma aplicação no município de } \\
\text { cabaceiras-PB }\end{array}$ & $\begin{array}{l}\text { Vasconcelos } \\
\text { Cândido (2012) }\end{array}$ \\
\hline $\begin{array}{l}\text { ISM - Índice de } \\
\text { sustentabilidade } \\
\text { municipal }\end{array}$ & $\begin{array}{l}\text { Qualidade de vida } \\
\text { humana; pressão } \\
\text { antrópica e capacidade } \\
\text { política institucional }\end{array}$ & $\begin{array}{l}\text { Índices de sustentabilidade municipal } \\
\text { o desafio de mensurar. }\end{array}$ & $\begin{array}{l}\text { Braga, Freitas e } \\
\text { Duarte (2003) }\end{array}$ \\
\hline
\end{tabular}

Fonte: Elaboração própria

\section{Algumas contribuições da atividade mineral para municípios mineradores.}

A atividade mineral surge como alternativa de desenvolvimento em áreas privilegiadas por essa atividade, porém com o passar dos anos esse olhar foi sendo ampliado ou incluídas as questões voltadas à sustentabilidade.

De acordo com Radelzki apud Enriquez (2007), as economias pobres, mas bem dotadas de recursos minerais devem extrair o quanto antes as suas jazidas, pois a mineração pode exercer um papel crucial no seu processo econômico. No entanto, a autora ainda enfatiza que da associação entre a mineração e desenvolvimento surgem novas possibilidades econômicas logo que se inicia a atividade mineral, como: descobertas de novas jazidas, multiplicação da renda e do emprego, criação, estruturação e fortalecimento institucional, sistema fiscal, organizações de fomento e apoio, sistemas de regulação, sistemas de financiamento e apoio, entre outros. Destaque para o capital humano capacitado para lidar com o setor e, por consequente, pronto a utilizar produtivamente a renda mineral gerada.

Basicamente essa renda mineral gerada para o município minerador vem da arrecadação da CFEM, que atualmente é repartida entre União (12\%), Estados (23\%) e Municípios produtores (65\%). Tal recurso surge, porém, como nova alternativa de desenvolvimento para os municípios, uma vez que são eles os maiores beneficiados. Uma das maiores vantagens desse recurso para os municípios é dada pela não atribuição específica a gastos, permitindo o setor público ter ampla flexibilidade para direcioná-lo, principalmente nas questões de câmbio sustentáveis.

Segundo Enriquez (2007), no Brasil, por volta de 1700 municípios mineradores recebem recurso financeiro da CFEM. Deste universo, apenas 27 municípios já respondem pela maior parte da 
arrecadação, ou seja, $81 \%$. Isso mostra que os maiores produtores é quem se prevalecem da grande demanda deste recurso. Apesar de tudo, o uso da CFEM pode ser visto como instrumento indutor de desenvolvimento local em regiões mineradoras. Já para municípios cuja essa arrecadação não seja tão volumosa, ainda assim é um recurso estratégico por conta de sua flexibilidade de investimentos. Por outro lado, municípios que tenham muitas indústrias mineradoras conseguem adquirir mais vantagens em arrecadação além do CFEM, como o ICMS, ISS, IPTU, entre outros, conseguindo incrementar a economia local, além dos empregos que são gerados.

Segundo Eggert (2000), o tratamento da sustentabilidade econômica para manter a contribuição da atividade mineral depende de alguns pontos como: riqueza mineral gerada; investimento em outras atividades para a manutenção do nível de bem-estar social quando a atividade mineral se encerrar; e políticas governamentais para controle dos potenciais efeitos macroeconômicos negativos.

Contudo, outras contribuições também serão direcionadas, como afirma Enriquez (2007), com as quais as comunidades podem ter vários benefícios; entre eles, aumento das oportunidades de diversificação da economia, ampliação do valor do território, expansão dos benefícios tradicionais, como empregos diretos, apoio às atividades econômicas, oferta de água e de energia, de transporte e de outras infra-estruturas, além de educação, saúde entre outras oportunidades. Porém, esses são benefícios que sempre tiveram pautados dentro do próprio sistema mineral, como afirma Veiga et al. (2005), as companhias mineradoras precisam pensar muito além desses benefícios tradicionais.

Entretanto, segundo Enriquez (2007), para se analisar uma região cuja base econômica seja a exploração e uso de recursos não-renováveis só deverão ser usados os conceitos de sustentabilidade "Fraca ou Sensata". Desse modo, a autora justifica duas bases de perspectivas, sendo uma a geração atual (intrageração), minimizando os danos ambientais, aumentando o bem-estar social; e outra a perspectiva da geração futura (intergeração), na qual a atividade deve gerar fluxo permanente de rendimentos para garantir o nível de bem-estar.

Para Veiga et al. (2005), uma comunidade será sustentável, caso siga princípios de sustentabilidade ecológica, da vitalidade econômica e da equidade social. Entretanto, Enriquez (2007) afirma a importância de um bom gerenciamento ambiental, porém ainda insuficiente para alcançar as dimensões do desenvolvimento em nível local. A autora ainda sugere que iniciativas nas áreas de comunicação, educação, saúde, segurança, parcerias e diversificação são elementos fundamentais para a sustentabilidade da comunidade a longo prazo.

\section{Considerações finais}

A visão alusiva de desenvolvimento de um município, sobretudo para aqueles que têm como principal atividade econômica a extração mineral, foi mudando nessas últimas décadas. $\mathrm{O}$ princípio que mantinha a ideologia de que essa atividade traria desenvolvimento mudou a partir da expansão do desenvolvimento sustentável, viabilizando novas formas e possibilidades de desenvolver uma atividade mais justa. Fundamental é fornecer alternativas que façam com que esses recursos minerais garantam sua permanência para futuras gerações e criem novas alternativas econômicas, caso haja o seu esgotamento.

Por sua vez, esse estudo aponta algumas contribuições que municípios mineradores podem vir a desenvolver, caso essas ações sejam embasadas nos pilares da sustentabilidade. Com isso, averiguam-se novas possibilidades de se saber até que ponto essa atividade econômica de fato pode trazer desenvolvimento para o município, diminuindo os impactos causados ao meio natural e humano, e até que ponto podem, através do uso de indicadores de sustentabilidade, direcionar a uma educação ambiental adequada, desde a empresa de mineração até o pequeno minerador, moldando suas necessidades, desenvolvendo um processo de aprendizagem sobre a melhor forma de gerenciar um possível empreendimento, levando em conta desde os aspectos legais, ambientais, econômicos, técnicos, até os culturais, sociais, dentre outros.

Porém, a análise desses aspectos dentro das dimensões ambiental, social e econômica mostra que a mineração só poderá almejar um desenvolvimento sustentável, se houver uma troca de valores, onde seus lucros obtidos no setor econômico possam ser revertidos em outras possibilidades de desenvolvimento, como o ambiental e o social. Essa troca ou inversão de valores deve ser aplicada em todo o setor para que haja engajamento do tripller da sustentabilidade.

Portanto, com o reconhecimento de todos os entraves causados pela atividade mineral, seus ganhos também são substanciais, à medida que a partir da CFEM os municípios mineradores possam ter uma gestão que estimule uma melhor 
distribuição desse recurso e contribua para um desenvolvimento de ações direcionadas ao bemestar social, a multiplicação da renda e do emprego, fortalecimento institucional, apoio a outras atividades econômicas, como também a utilização mais eficiente dessa renda mineral gerada, entre outros.

\section{Agradecimentos}

A Capes pela concessão de bolsa de estudo para o desenvolvimento deste trabalho e ao programa de pós-graduação em Recursos Naturais - UFCG.

\section{Referências}

Amade, P., Lima, H.M. de., 2009. Desenvolvimento sustentável e garimpo - O caso do Garimpo do Engenho Podre em Mariana, Minas Gerais. Revista Escola de Minas Gerais - REM, 62, 237-242

Araújo, M.C.C., Cândido, G.A., 2014. Qualidade de vida e sustentabilidade urbana. Revista Holos - Instituto Federal de Educação Ciência e Tecnologia do Rio Grande do Norte (IFRN) 01, 3-19.

Azapagic. A., 2004. Developing a framework for sustainable development indicators for the mining and minerals industry. Journal of Cleaner Production 12, 639-662.

Barreto, M.L., 1992. Ensaios sobre sustentabilidade da mineração no Brasil, 1 ed. CETEM/MCT, Rio de Janeiro.

, 2001. Mineração e desenvolvimento sustentável: Desafios para o Brasil, 1 ed. CETEM/MCT, Rio de Janeiro.

Braga, T.M. et al., 2003. Índices de sustentabilidade municipal: o desafio de mensurar. UFMG/Cedeplar, Belo Horizonte. (Texto para discussão; 225).

Bellen, H.M.V., 2005. Indicadores de sustentabilidade: Uma análise comparativa. 2. ed. FGV. Rio de Janeiro.

Cândido, G.A., Vasconcelos, A.C.F., Souza, E.G., 2010. Índice de Desenvolvimento Sustentável para Municípios: uma proposta de metodologia com a participação de atores sociais e institucionais. In: CÂNDIDO, G. A. (Org). Desenvolvimento Sustentável e Sistemas de Indicadores de Sustentabilidade: Formas de aplicações em contextos geográficos diversos e contingências específicas. Ed. UFCG Campina Grande - PB, 87-117.

CONAMA - Conselho Nacional do Meio Ambiente., 1986. IBAMA. Resolução Conama no001/86. Publicada no Diário Oficial da União, DF.

Dantas, H.F.S. de A.; Freitas, L.S, 2014 Sustentabilidade da Industria mineral no município de Pedra Lavrada - PB: Um estudo a partir do uso do ISM - Índice de Sustentabilidade da Mineração. Revista Universo Contábil 10, 144.

DNPM - Departamento Nacional da Produção Mineral., 2006/2007/2008/2009/2010. Anuário Mineral Brasileiro. Disponível: <http:www.dnpm.gov.br >. Acesso em: 20 jun. 2016.

Eggert, R. G., 2002. Sustainable and the mineral industry. In James M. Otto e John Corde (editores) Susteainabe Development and the future of mmineral Investment Paris, United Nations Environnment programme.

Enríquez, M.A.R. da S., 2009. Mineração e desenvolvimento sustentável: é possível conciliar? Revista Iberoamericana de Economía Ecológica, 12, 51-66. 2007. Maldição ou Dádiva? Os dilemas do desenvolvimento sustentável a partir de uma base mineira. Tese de doutorado em Desenvolvimento Sustentável. Centro de Desenvolvimento Sustentável da Universidade de Brasília, CDS/UnB.

Farias, C.E.G., 2002. Mineração e meio ambiente no Brasil. Disponível: <http://www.cgee.org.br/arquivos/estudos>. Acesso em: 12 mai. 2014.

Fernandes, F.R.C.; Lima, M.H.M.R.; Texeira, N. da S., 2011. Grandes Minas do Semiárido Brasileiro e o Desenvolvimento Local. In: Recursos Minerais e Sustentabilidade Territorial: Grandes minas. (Eds.): CETEM/MCTI, Rio de Janeiro.pp. 98-111.

Fernandes, I.C., Sauer, L., 2011. Indicadores Sociais Sintéticos no Planejamento de Políticas Públicas - o Índice de Qualidade Institucional dos Municípios (IQIM) e o Índice do Potencial de Desenvolvimento do Município (IPDM). Disponível:

http://www.propp.ufms.br/gestor/titan.php?targ et $=$ openFile \&fileId $=593$. Acesso em 30 de novembro de 2016.

Granda, W.J.V.; Lima, H.M., 2006. Aplicação do Índice Global de Sustentabilidade na Exploração de Coquinha na Península de Santa Helena. REM: Revista Esc. Minas, Ouro Preto.

González, A., Carvajal, D., 2002. Sustainability Indicators in the Spanish Extractive Industry. In: Indicators of sustainability: For the mineral 
extraction industries. CNPq/CYTED Rio de Janeiro.

IBRAM - Instituto Brasileiro de Mineração., 1987. Mineração e meio ambiente: Impactos previsíveis e formas de controle. 2. ed. Comissão Técnica de Meio Ambiente, Belo Horizonte.

IBGE - Instituto Brasileiro de Geografia e Estatísticas. 2010. Informações do Brasil. Disponível:

<http://www.informacoesdobrasil.com.br/dado s/paraiba/pedra-lavrada/mapa-pobrezadesigualdade/>. Acesso em: 24 nov. 2015.

. Perfil dos municípios brasileiros 2010.

Disponível em:

<http://www.sidra.ibge.gov.br/bda/tabela/prota bl.asp?c=21\&z=p\&o=37\&i=P>. Acesso em: 24 nov. 2015.

Jara, C.J., 1998. A Sustentabilidade do desenvolvimento local. Brasília - Instituto Interamericano de Cooperação para a agricultura (IICA)., Secretaria de Planejamento do Estado de Pernambuco - Seplan. Recife:

Kopezinski, I., 2000. Mineração x Meio ambiente: Considerações legais, principais impactos ambientais e seus processos modificadores. Ed. Universidade/UFRGS, Porto Alegre.

Lamego. F.; Fernandes. H.; Franklin. M., 2002. Mineração de Urânio e Energia: Indicadores de Sustentabilidade Ambiental, Econômica e Social. In: Indicadores de Sostentabilidad para La industria Extrativa Mineral. Rio de Janeiro: CNPq/CYTED, 163-178.

Lins. F.A.F; Loureiro F.E.V; Albuquerque, G.A.S.C.A., 2000. Brasil 500 anos- A Construção do Brasil e da América Latina pela Mineração. CETEM/MCT. Rio de Janeiro.

Madureira, H., 2005. "Paisagem Urbana e Desenvolvimento Sustentável - Apontamentos sobre uma Estreita Relação entre Geografia, Desenvolvimento Sustentável e Forma Urbana”, X Colóquio Ibérico de Geografia, 22 a 24 Setembro, Évora, Portugal.

Malheiros, T.F.; Coutinho, S.M.V.; Philippi Jr, A. 2012. Desafios do uso de indicadores na avaliação da sustentabilidade. In: Indicadores de Sustentabilidade e Gestão Ambiental. Malheiros, T.F. e Philippi Jr, A. (Org). Editora Manole, Barueri - SP.

Mitchell, G., 1996. Problems and fundamentals of sustainable development indicators. Sustainable Development 4, pp.1-11.

Moreira, H. F., 2002 O desenvolvimento sustentável no contexto do setor mineral brasileiro. Monografia (Especialização) Curso de Pós-Graduação em Gestão
Ambiental, Rio de Janeiro, Universidade Federal do Rio de Janeiro - UFRJ.

Nahas, M.I.P.; Pereira, M.A.M.; Esteves, O. de A.; Gonçalves, É., 2006. Metodologia de construção do índice de qualidade de vida urbana dos municípios brasileiros (IQVU-BR). In: XV Encontro Nacional de Estudos Populacionais da Associação Brasileira de Estudos Populacionais. Disponível em: <www.abep.nepo.unicamp.br/encontro2006/.../ ABEP2006_420.pdf>. Acesso em: 15 mar. 2015.

Parizotto, J.A., 1995. O Gerenciamento Ambiental: Estudo de caso de cinco empresas de mineração no Brasil.ed. UNESP, Especialização em Proteção Ambiental. Rio de Janeiro.

Pimiento. E.V., 2002. Indicadores de Sostentabilidad y de Desempeño Socioambiental para los Grupos de Usuarios Mineros en Colombia. In: Indicadores de Sostentabilidad para La industria Extrativa Mineral.: CNPq/CYTED, Rio de Janeiro, pp.163-178.

Ross, J.L.S., 2005. Ross, J. L. S. Geografia do Brasil. EDUSP. São Paulo.

Sales, R.M.M; Cândido.G.A; Sales, L.G.L., 2012. Indice de Desenvolvimento Sustentável Municipal (IDSM). Uma aplicação nos municípios que compõem a sub bacia do Médio Piranhas no estado da Paraíba. Disponível:

http://www.anppas.org.br/encontro6/anais/AR QUIVOS/GT14-362-99-20120621202446.pdf . Acesso em: 20 de mar. 2015.

Strauch, J.C.M; Souza, K. V. de S; Ajara, C.; Teixeira, M. de P.; Cardoso, C.S., 2011. Grandes Mineradoras e a comunidade de Niquelândia. In: Recursos Minerais e Sustentabilidade Territorial: Grandes minas. (Eds.): CETEM/MCTI, Rio de Janeiro, pp 135161.

Tilton, J. E., 2004. Determining the optimal taro on mining. In Natural Resources Forum, Blackwell Publishing Ltda 28, USA, pp. 144150.

Vale, E., 2002. Indicators of sustainability for the mining industry. ISIEM, Carajás, Pará, Brasil.

Vasconcellos, E.M., 2002. Desenvolvimento Sustentável Local: $\mathrm{O}$ caso de Canela. Dissertação de Mestrado. Porto Alegre, Universidade Federal do Rio Grande do Sul..

Veiga, J. E. da., 2005. O prelúdio do desenvolvimento sustentável. In: OLIVA, Pedro Mercadante. (Org.). Economia Brasileira: Perspectivas do Desenvolvimento. 
São Paulo, SP: Centro Acadêmico Visconde de Cairu, São Paulo, pp. 243-261.

Viana, M.B., 2007. Licenciamento ambiental em minerações de Minas Gerais: novas abordagens de gestão. Dissertação (Mestrado em Desenvolvimento Sustentável) Universidade de Brasília, Brasília.

Viana, M. B., 2012. Avaliando minas: Índice de Sustentabilidade da Mineração (ISM). Tese de Doutorado. Centro de Desenvolvimento Sustentável. Universidade de Brasília.

Villas-Bôas, R. C.; Beinhoff, C.,2002. Indicadores de sostenibilidad para la industria extrativa mineral. CNPq/CYTED, Rio de Janeiro.
Villas-Bôas, R.C. ed. et al., 2005. A review on indicators of sustainability for the minerals extraction industries CETEM/MCT/CNPq/CYTED/IMPC, Rio de Janeiro.

Villas-Bôas, R.C., 2009. Indicadores de desenvolvimento sustentável para a indústria extrativa mineral: Guia prático. CETEM/MCT/CNPq/CYTED, Rio de Janeiro.

Villas-Bôas, H.C., 2011. A indústria extrativa mineral e a transição para o desenvolvimento sustentável. CETEM/ MCT/Cnpq, Rio de Janeiro. 